\title{
Implications for medical genetics of the House of Commons Science and Technology Committee's report on human genetics
}

The House of Commons Science and Technology Committee's report ${ }^{1}$ follows consultation in Britain and in the USA with an impressive list of those giving evidence and a very wide scope, from genetics in the Health Service to ethical issues thrown up by the Human Genome Programme. The importance of genetic education of the population, schools, medical schools, and professions is stressed and the report calls for a Human Genetics Commission to be established by Act of Parliament to oversee the whole subject.

Cynics will claim that we have had enough exhortations ${ }^{2}$ and reports on genetics services in Britain ${ }^{3-11}$ and now we need adequate funding and implementation. However, comparison with Europe ${ }^{1213}$ shows how much has been achieved by professionally led initiatives with consistent long term planning and cooperation between geneticists, regional health authorities, medical Royal Colleges, and Departments of Health so that successive reforms of the Health Service have challenged ${ }^{1415}$ but have not so far blocked progress. As a result there are well planned genetic services in the UK, ${ }^{16}$ albeit still underfunded, based on regional genetics centres where the principle of "under one roof" 1718 has encouraged integration and consequent high quality services for patients and their families. This is mirrored by the British Society for Medical Genetics, a coalition of the four complementary specialties: clinical genetics, cytogenetics, molecular genetics, and genetic nurses and social workers. It is also recognised that medical genetics is not the sole responsibility of specialists in rare genetic disorders because its effects are increasingly felt throughout medicine and society as a whole. Fortunately Britain has a well organised primary care system ${ }^{19}$ in which there is registration of almost $100 \%$ of the population with GPs who refer patients to specialists rather than encouraging self-referral, which is so common and so expensive in many countries. The gatekeeper function is not the only strength of the partnership between primary care and genetics. Pilot studies ${ }^{20}$ have shown that with the help of genetic centres, primary care teams successfully undertake counselling and genetic population screening, and this will become increasingly important as workloads escalate from genetic screening for common disease susceptibility. ${ }^{21}$ Informing patients, acting as their advocates, and protecting them from overinvestigation, as well as appropriate referral to specialist, are all vital contributions by primary care.

However, unprecedented molecular genetics developments coupled with raised public expectations have to be accommodated within an NHS subjected to radical change. An internal market in health care, the purchaserprovider split, and the demise of the old regional health authorities, all threaten regional services. Although groupings of health districts with lead purchasers have in some places been established to allow funding strategies based on a decent sized population base, the latest initiative from the NHS Executive encourages the devolution of priority setting for genetics to fund holding GPs. Few GPs would have list sizes big enough to allow rational planning of services for genetic disorders, most of which are too rare to allow a GP to have had meaningful experience of them. The situation is further complicated by important changes, to be implemented by 1998, in the method of funding NHS research and development following the Culyer report. ${ }^{22}$

Will these NHS reforms damage the ability of genetics services and research to match clinical and population needs? In the increasingly commercial environment of British health care will purchasers demand inappropriate outcome measures and will hard pressed medical geneticists be expected to deal with large scale genetic screening for susceptibility to common disease, or will other hospital specialities demand and receive development funds to duplicate existing genetic services? Who will regulate access by employers and insurance companies to genetic screening results and what are the implications of the spread of private laboratories and unregulated commercial patenting of human genes? Who will undertake the massive task of educating professionals and population?

These questions and others have been addressed in the Science and Technology Committee's report which, as noted earlier, calls for a Human Genetics Commission with statutory powers to implement its decisions. Specific recommendations include the need for monitoring the effects of NHS reforms on R\&D and on patients' access with monitoring of the quality of genetics services. The report recommends caution in adopting outcome measures for genetics services, recognising that many beneficial outcomes depend upon hard to measure results of accurate and empathic counselling which enable people to make autonomous decisions: the quality of genetics cannot be measured by counting abortions. The report notes that it is premature to devolve funding of services to the GP level, although more emphasis should be given to the partnership between genetic centres and primary care and the need to provide training and resources for these purposes.

Much of the earlier Nuffield Council on Bioethics report $^{23}$ is endorsed with unambiguous statements about difficult ethical issues. For example, all carriers of recessive disorders who are detected should be informed of their status and counselled appropriately and there should be regulation of commercial testing. Patenting of genes is acceptable providing patents link genes to a particular use and there is careful monitoring of the effects on health care systems. The report argues for a strict code of privacy preventing employers and insurance companies from having access to genetic information; insurance companies are given a year to come up with a policy or face legislation.

The report is well written, is comprehensive, and speaks with the authority of a well informed House of Commons committee. The Government is preparing its reply which will probably be debated in the House, but one hopes that the recommendations will receive all party support, so a general election might delay but probably not prevent implementation. How medical genetics then evolves is linked with health care systems and how these are regarded by different political ideologies and with the effects of closer integration with the European Union. The speciality also needs to consider how it should relate to the genetics of common disease and to the probability of consequential changes in medicine and health in the 21 st century. 
1 House of Common Science and Technology Committee. Human genetics: the science and the consequences. London: HMSO, 1995.

2 Harris R. Make way for the new genetics. BMF 1987;295:349-50.

3 Royal College of Physicians of London. Prenatal diagnosis and genetic screening. Community and service implications. London: Royal College of Physicians London, 1989.

4 Harris R, Elles R, Craufurd D et al. Molecular genetics in the National Health Service in Britain. $\mathcal{F}$ Med Genet 1989;26:219-25.

5 Royal College of Physicians London. Teaching genetics to medical students. London: Royal College of Physicians, 1990.

6 Royal College of Physicians of London. The retention of Medical Reconds in relation to genetic diseases. London: RCP, 1991.

7 Royal College of Physicians of London. Clinical genetic services in 1990 and beyond. A report of the Clinical Genetics Committee of the Royal College of beyond. A report of the Clinical
Physicians. London: RCP, 1991.

8 Royal College of Physicians of London. Ethical issues in clinical genetics. London: RCP, 1991

9 Johnston AW. Postgraduate teaching of clinical genetics in the United Kingdom. F Med Genet 1992;29:724-5.

10 Services for genetic disorders. Letter from the Chief Medical Officer and the Chief Nursing Officer: Population needs and genetic services - an outline guide. London: Department of Health, 1993. (PLCMO (93) 5 and PL CNO (93) 4).

11 Report of the Genetics Research Advisory Group. A first report to the NHS Central Research and Development Committee on the new genetics. London: Central Research and Development
Department of Health, July 1995.

12 Harris R, Rhind J. The speciality of clinical genetics: ESHG survey. 7 Med Genet 1993;30:147-52.
13 Harris R. Report of ESHG Satellite Meeting: EU Concerted Action on Genetic Services in Europe (CAGSE). Eur $f$ Hum Genet 1994;2:300-3 Annex 7.

14 Royal College of Physicians of London. Purchasers' guidelines to genetic services in the NHS. An aid to assessing the genetic services required by the resident population of an average health district. London: RCP, 1991.

15 Harris R. Genetic services in Britain: a strategy for success after the NHS and Community Care Act 1990. F Med Genet 1990;27:711-14.

16 Harris R. Medical genetics. BMF 1991;303:977-9.

17 Need for coordination in the development of effective genetic services. Joint statement from Royal Colleges of Physicians (London), Pathologists, Obstetricians and Gynecologists and General Practitioners. Unpublished (available from Hon Secretary, Committee on Clinical Genetics, RCP) 1986.

18 Reply from DHSS to Joint Statement. Available from Hon Secretary, Committee on Clinical Genetics, RCP.

19 Harris R, Harris HJ. Primary care for patients at genetic risk: a priority for EC concerted action on genetics services. BMF 1995;311:579-80.

20 Harris H, Scotcher D, Hartley N, Wallace A, Craufurd D, Harris R. Cystic fibrosis carrier testing in early pregnancy by general practitioners. $B M \mathcal{F}$ 1993;306:1580-3.

21 The Genetics of Common Disease. A second report to the NHS Central Research and Development Committee on the new genetics. London: Department of and Development Comm

22 Supporting Research and Development in the NHS. A report to the Minister for Health by a Research and Development Task Force chaired by Professor Anthony

23 Genetic screening, ethical issues. London: Nuffield Council on Bioethics (UK), 1993.

\section{Note added in proof}

The Government response to the Report on Human Genetics: implications for genetics services

The Government's response* is reported $†$ to have angered MPs by being "complacent and ignorant" particularly in rejecting a commission on the grounds that existing bodies cover the majority of issues for which such a commission would have been responsible. The Government is certainly not overexcited about the need for urgent action on the implications of molecular advances although there are some messages which are mildly encouraging to medical geneticists planning and running genetics services in the NHS. For example the response re-emphasises that the decision whether or not to undergo genetic testing is for the individual person and the decision must be informed by knowledge of the possible significance of the results for that person. Further the Government agrees with the Committee ". . . that people who seek diagnosis of a genetic condition of late onset, that is, in adult life, should be given adequate information about the medical and social implications of the findings and offered sufficient counselling, in advance of any testing, and subsequently if the

* Government Response to the Third Report of the House of Commons Select Committee on Science and Technology, 1994-95 Session. London: HMSO, $\mathrm{Cm} 3061$

t The Times Higher Education 19 January 1996 results of the test are positive". This implicitly recognises the need for enough trained professionals to cope with all this counselling. It goes further in recognising that ". . the coherence of the NHS means it is well placed to take advantage of new advances in genetics ...", thus giving tacit acceptance of the dangers of too many reforms. This is reinforced by the statement that "there is no intention to devolve funding for all (sic) the functions and elements, all the collaborative and co-ordinating roles of the genetic services to GP fundholders". This may do something to relieve the anxieties of medical geneticists, but they will still be worried that specialist genetic centres have to negotiate contracts with multiple health commissions, and without central guidelines on contracts. Fortunately the response is cautious in describing what purchasers should expect from genetic services as outcome measures. These should be "... judged by the degree to which individuals and couples at risk are identified and given timely information that is sufficiently precise to enable them to make informed decisions on the interventions available".

Not really the dramatic progress that some had hoped for but at least another step in the long process of building genetics services. How medical genetics actually evolves is inevitably linked with current realities and how health care systems are regarded by different political ideologies. But medical geneticists must collaborate with primary care and others to contribute to health services at the millenium. 